Article

\title{
Learning and Emotional Outcomes after the Application of Invention Activities in a Sample of University Students
}

\author{
Eduardo González-Cabañes ${ }^{\circledR}$, Trinidad García *(D), Celestino Rodríguez ${ }^{\circledR}$, Marcelino Cuesta \\ and José Carlos Núñez
}

Department of Psychology, University of Oviedo, 33003 Oviedo, Spain; gonzalezventura@uniovi.es (E.G.-C.); rodriguezcelestino@uniovi.es (C.R.); mcuesta@uniovi.es (M.C.); jcarlosn@uniovi.es (J.C.N.)

* Correspondence: garciatrinidad@uniovi.es; Tel.: +34-985103259

Received: 29 July 2020; Accepted: 3 September 2020; Published: 6 September 2020

\begin{abstract}
Invention activities can promote reflective learning processes. However, their inclusion in educational practice can generate doubts because they take up time that can otherwise be invested in explaining content, and because some students might experience frustration and anxiety while trying to solve them. This study experimentally evaluated the efficacy of invention activities in a university statistics class, considering both emotions (self-reported) and learning achieved. In total, 43 students were randomly assigned to either (a) inventing variability measures before receiving instruction about the topic of statistical variability, or (b) completing a similar problem-solving activity, but only after they had received guidance with a worked example concerning the target concepts. Students in the first condition acquired greater conceptual knowledge, which is an indicator of deep learning. The emotions experienced during the learning activities were similar in both learning conditions. However, it was notable that enjoyment during the invention phase of the invention condition was strongly associated with higher achievement. Invention activities are a promising educational strategy that require students to play an active role, and can promote deep learning. This study also provides implementation guidelines for teachers while discussing the possibilities offered by new technologies.
\end{abstract}

Keywords: inventing to prepare for future learning; productive failure; reflective thinking; self-regulated learning; innovations for flipped classroom; transfer

\section{Introduction}

It is important that students acquire a deep understanding of the concepts they study, and that they are able to transfer these concepts to novel situations. Our society faces challenges that require us, both as individuals and groups, to apply our knowledge with flexibility and autonomy [1]. This capacity is crucial in facing future challenges, such as environmental respect, the maintenance of social justice, and the balance of these objectives with economic growth in a globalized economy [2].

A promising approach is the Inventing to Prepare for Learning (IPL) approach [3,4]. It consists of providing students with the opportunity to generate personal solutions to a problem related to a new concept before a formal explanation of the new concept is delivered, while also taking advantage of the invention experience as preparation for further instruction. For example, before explaining the topic of statistical variability, students can be asked to invent their own ways to measure variability. Several studies have shown the efficacy of this method in promoting conceptual knowledge, which refers to a deep understanding of the contents learned, and transfer, which refers to the ability to apply the contents learned in new contexts [3-6]. However, these types of interventions can generate concern because they might interfere with the time available for the delivery of lesson content, or because some 
students might not have the cognitive or emotional capabilities to benefit from such a challenging experience $[6,7]$. The objective of this study is to contribute to exploring the efficacy of this approach through a controlled experiment conducted in a university statistics class, while considering both the knowledge acquired by students and their emotional responses.

\subsection{Inventing to Prepare for Learning (IPL)}

IPL is a specific approach based on the more general approach of problem-solving before instruction, similarly to other specific approaches such as productive failure [8]. That is, it is characterized by the combination of two educational phases when introducing a new concept to students: an initial phase of creative problem-solving related to the concept to be learned, and then an instruction phase, wherein the concept is explained and students compare the solutions they generated with the explanations $[3,4]$. However, what particularly characterizes IPL is the use of two complementary strategies to help students assimilate information during the initial phase: contrasting cases and invention goals [3,5].

Contrasting cases consists of presenting the data of the problem to be solved with simplified cases that differ only in one or two relevant characteristics. This strategy allows the students to easily compare the cases side-by-side, thus focusing the attention of the students on the relevant features of the problem, and facilitating the students' reliance in their own understanding and intuition to formulate and self-evaluate solutions [3]. For example, in the invention problem used in this study (Figure 1), students were asked to explore income inequality (or income variability) across the inhabitants of four imaginary countries. It was simplified so that there were only four to seven inhabitants living in each country, and their rent was expressed as small integers (from 0 to 10) to facilitate calculations. When comparing two countries side by side, it can be observed that they have similarities in some relevant characteristics. For example, when comparing Pinpanpun and Toveo, it can be seen that they have the same range, same mean, and same number of cases. However, they differ in an important characteristic, that is, the income distribution differs beyond the two scores that establish the range. Through this differentiation, most students would be able to intuitively rank which country has the highest inequality.

The challenge of the problem comes from the invention goal, which requires students to generate a general procedure, in this case a quantitative index, to systematically compare any pair of cases presented, or even cases not presented in the exercise [3]. That is, they must invent a mathematical formula that integrates the characteristics they think are important, and the relationship between these characteristics. It is not expected that they invent a way to explain the target concept that is to be explained later in the instruction phase [5], which in this case would have them discovering the formula for standard deviation. However, it is expected that they critically reflect on the relevant features of the concept [5], generate and activate personal ideas that can help in assimilating further explanations $[9,10]$, and become aware of their knowledge gaps [11]. Furthermore, students may also experience increased motivation to learn because of the responsibility of assuming a creative role [9].

Nevertheless, IPL can also have potential negative effects. Some students can feel over-challenged with the different options to consider during the invention tasks. Further, during the time invested in this activity, it is possible that students pay attention mostly to solutions not related to the target concept [12]. In this regard, several studies have shown that extraneous cognitive load, a sensation of attentional saturation because of processing aspects that are not related to the learning objective [13], was higher in students who performed the invention activity of IPL than in students who directly received explanations about the target concepts $[6,7,14]$. Yet, it is important to note that this invention phase is just a transitional phase. What is initially perceived as extraneous cognitive load in the invention phase can become germane cognitive load, or cognitive load related to the learning objectives [13], in the posterior instruction phase. More specifically, the exploration of different alternatives that do not match the target concept, although perceived as random ideas, can be significant for further learning as students become aware of the reasons why these alternatives do not work. Based on these different 
possibilities, it is of great importance that the efficacy of IPL is evaluated in terms of comprehension and capacity to transfer knowledge at the end of the learning process.

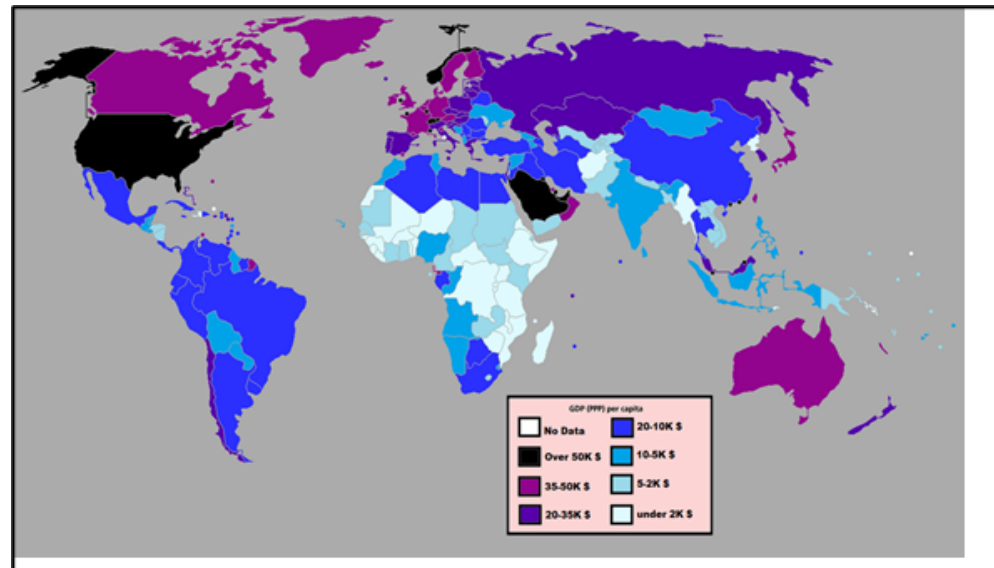

This image shows the average income (GDP per capita) of the countries in 2012. We can see that, for example, Spain and Russia have a similar average income. However, is the average income alone enough to give us an idea of the wealth of the inhabitants?

Below you can see 4 imaginary countries. Although the average income is the same in all of them, it is easy to see that they differ on how strongly inequality affects the wealth of their inhabitants.

How can we measure inequality?

Try to design a mathematical index that would help us measure and compare inequality in these 4 countries. You can give multiple answers. There is no one unique valid solution!

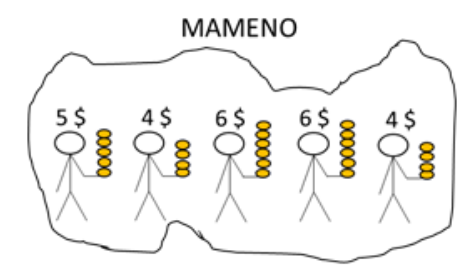

Average Income: $(5+4+6+6+5) / 5=5$

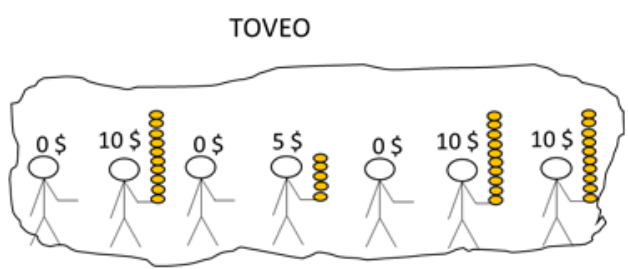

Average Income: $(0+10+0+5+0+10+10) / 7=5$

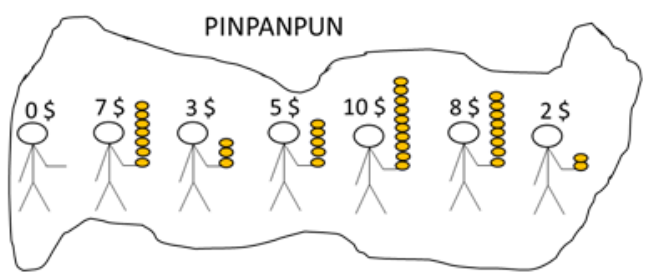

Average Income: $(0+7+3+5+10+8+2) / 7=5$

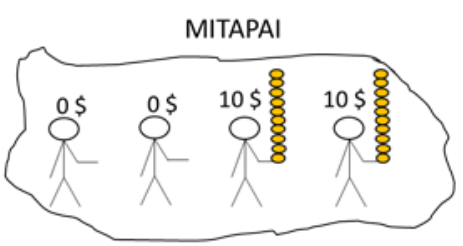

Average Income: $(0+0+10+10) / 4=5$

Figure 1. Invention problem used in the IPL condition.

In this sense, several studies support the efficacy of IPL in promoting deep learning $[3,5,6]$. For example, in one study [5], high school students in a physics class were assigned to one of two possible conditions for learning the concept of density. In the invention condition, students started the lesson with an invention problem, where they had to invent a "crowdedness index" to compare how crowded different buses were, before receiving a lecture about density, the target concept related to crowdedness. In the control condition, students used the same learning materials and completed the same activities; however, before completing the invention activity, they received instruction with a worked example whereby they studied the concept of density and the resolution procedures of a similar problem. Therefore, in this control or fully guided condition, the crowdedness invention activity instead became a practiced problem wherein they had to apply the density formula already learned. Results showed that students who began with the invention stage demonstrated a higher 
codification of the structural components of the problem, as well as a higher capacity to transfer the knowledge acquired to new problems.

Similarly, evidence from meta-analyses [15] and systematic reviews [16] also supports the advantage of completing problem-solving before instruction in comparison to alternative strategies wherein students start the learning process by receiving explanations. Specifically, although no differences between the approaches were generally found in terms of procedural knowledge [16], which just refers to the capacity to reproduce the procedures taught, students who problem solved before instruction generally outperformed other students in terms of conceptual knowledge and transfer $[15,16]$. Furthermore, this advantage of problem-solving before instruction versus alternative approaches was more pronounced for studies conducted using the IPL strategy of contrasting cases [16].

In spite of this evidence supporting the general efficacy of IPL in promoting enhanced learning of content, it is important to note that most studies have been conducted at primary education or high school levels $[15,16]$. There is a need for more evidence of its efficacy in university contexts. To contribute to the generalizability of IPL, the present study was conducted in a university class of statistics, wherein the efficacy of IPL was compared to the efficacy of a learning strategy in which new concepts were introduced with a worked example. A worked example is a problem presented together with the resolution procedures and explanations. Therefore, all students were given the same problem, but instead of simply searching for solutions like students in the IPL condition, students in the control condition were fully guided towards the resolution procedures and given the important ideas.

Also, it is important to consider the variability of emotions that different students can experience during IPL, because this variability can act as a disincentive for educators to translate IPL into real practice. The potential feeling of being over-challenged and the cognitive load experienced by students during the initial invention phase can generate confusion, anxiety and frustration [12]. These emotions are of great relevance to researchers and teachers, as emotions often provide an immediate feedback from student to teacher, and teachers might avoid activities associated with negative emotions.

\subsection{Invention and Emotions}

There is an increasing awareness of the impact of emotions on learning [17-19]. However, emotions have rarely been investigated in the context of IPL. The only relevant reference the authors are aware of is a study that only focused on the emotion of curiosity; the study showed that curiosity was higher in students who invented first than in students who were fully guided with a worked example [7]. However, the associations between curiosity and learning were not clear. It is also important to note that in this study, extraneous cognitive load, a sensation that can lead to higher frustration and anxiety [12], was higher in the invention phase of the IPL condition than in the worked example phase of the control condition [14]. Indeed, it was one of the few studies that found better learning outcomes in the control condition than in the IPL condition. To better explain this and other conflicting results, it is necessary to consider a broader range of emotions that might be experienced during invention activities. Specifically, in the present study we will consider the seven epistemic emotions, that is, emotions defined as having implications for learning [17]: surprise, curiosity, enjoyment, confusion, anxiety, frustration and boredom.

It can be expected that the process of inventing might lead students to experience intense emotional reactions, both positive and negative. On the one hand, the novelty and the creativity that students experience might lead them to feel high levels of curiosity and enjoyment; both of these are motivating emotions that have been associated with knowledge acquisition and effective learning strategies [20-22]. On the other hand, the over-challenge and the cognitive load students might experience during invention activities might also lead them to experience confusion, anxiety and frustration [12].

The consequences of these negative emotions can be variable. They are intense emotions that consume mental resources, which in turn can lead to the use of more rigid and automatic learning strategies, such as strategies based purely on memorization [23]. They can also undermine intrinsic 
motivation [22]. Nonetheless, they can also induce extrinsic motivation to avoid failure. These opposing mechanisms might explain why the association between learning and these three negative emotions has been variable in the literature [22]. Additionally, within the specific context of IPL, these emotions might have different implications as they might be more transitional than in other learning contexts. In IPL, the invention phase is transitional, and negative emotions experienced during the invention phase might be motivating during later learning phases. Some studies have suggested that the emotion of confusion, when transitional, was associated with reflective strategies and higher learning [20,24].

Considering these various possibilities, it is of great importance to experimentally evaluate the role of emotions in IPL. Furthermore, it is important to explore which cognitive conditions, for example, the differences in students' previous knowledge, might be associated with experiencing different emotions. On the one hand, higher previous knowledge can constitute a resource for facing the challenge of the invention task, and therefore it can be expected that higher previous knowledge would be associated with experiencing more positive emotions. However, on the other hand, the opposite results can be expected. Some authors have hypothesized that students with low previous knowledge would be the ones who enjoy more invention activities due to the opportunity to rely on personal ideas [8]. If the latter is true, invention activities might help reduce the learning gap between students with higher previous knowledge and those with lower previous knowledge.

Being aware of students' variability, their emotional reactions and the implications of these emotions in learning can help educators make a conscious decision regarding the introduction of IPL into their classes. Finally, considering the scarcity of research on IPL in university settings $[16,25]$, it is important to evaluate IPL within these populations.

\subsection{Study Aims and Hypotheses}

This study evaluated the efficacy of the IPL approach in terms of learning and emotional correlates in a sample of university students. Students were enrolled in an introductory statistics course in the major of psychology, in the University of Oviedo (North Spain). Within the same class, half of the students were assigned to IPL-inventing a variability index before covering the topic of statistical variability--while the other half of the students were instead prepared with a worked example and a related practice problem. Specifically, the study aims were:

- To evaluate the efficacy of IPL, in comparison to being fully guided from the beginning with a worked example, in promoting procedural knowledge, conceptual knowledge and the transfer of knowledge in a sample of university students. We hypothesized that because of the reflective processes stimulated during the invention tasks, the students who learned through IPL would score higher in conceptual knowledge and transfer than those who were initially prepared with the worked example;

- To examine the different evolution of emotions experienced by students in these two learning conditions. We hypothesized a higher intensity of both positive and negative emotions for students in the IPL condition than for students who were initially prepared with the worked example, because of both the creative component and the expected challenge of the invention task;

- To explore how students' emotions were associated with the knowledge acquired at the end of the lessons in each of the two learning conditions. We hypothesized that learning would be associated with the motivating emotions of curiosity and enjoyment, but not with the negative emotions of confusion, frustration or anxiety, for which there is more variability in their potential implications;

- To analyze how students' previous knowledge was related to these learning and emotional outcomes. We did not hypothesize a specific direction for these relations because of the variability of potential implications that previous knowledge can have on the emotional response during invention tasks. 


\section{Materials and Methods}

\subsection{Participants}

A convenience sample of 43 university students (year 1) took part in the study. Of the total, 74.4\% were female, and their ages ranged from 17 to 19 years old $(\mathrm{M}=17.952, \mathrm{SD}=0.909)$. They were all taking a course on statistics at a state university in northern Spain. This group of students was divided into two conditions, assigned within the same classroom: the invention condition $(n=22$; $63.6 \%$ women; Mage $=18.191$, SDage $=1.233)$ and the control, or fully guided, condition $(n=21 ; 85.7 \%$ women; Mage $=17.714$, SDage $=0.560)$. Beyond these students, three additional students in the class were not considered in the data analysis because they did not complete the procedures. Two of these were initially assigned to the invention condition during the first class session of the experiment, but they did not attend the second class session where the complementary learning and experimental evaluations continued. The other student only came to the second of the class sessions in which there was no assignment to conditions.

\subsection{Study Design and Procedures}

The experiment was carried out during two 60 minute class sessions of an introductory course in statistics in the major of psychology. During these sessions the topic of statistical variability was covered. In recent class sessions, students had covered the topics of measures of position, central tendency, and general introductory statistics concepts such as measurement and different research designs. The two sessions were led by the first author, who was not the professor of the course. He had previous experience teaching in other courses of statistics. The procedures followed the protocol in [26]. A summary of the general design can be observed in Figure S1.

\subsubsection{Ethical Procedures}

This investigation was approved by the Ethical Committee for the Investigation of the Principality of Asturias (Reference: 242/19). Before starting the study, the students received detailed information about its aims and scope and provided informed consent. They were informed that they could participate in the learning activities and evaluation exercises, as in any regular class, but they were free to choose whether or not to hand in the questionnaires and evaluations pertaining to the investigation.

\subsubsection{Measurement of Previous Knowledge}

At the beginning of the first session, students were given $10 \mathrm{~min}$ to complete a previous knowledge pre-test (see Pre-test in Supplementary Materials). This pre-test contained questions and exercises relevant to understanding the variability content of the experiment, such as central tendency and measures of position. To avoid the possibility that this pre-test could act as an invention activity, and thereby contaminate the experimental results [27], it did not cover any statistical variability content.

\subsubsection{Assignment to the Two Learning Conditions}

Immediately following the previous knowledge pre-test, the experimenter randomly assigned the materials that were specific to the two learning conditions. That is, he walked around the classroom and handed a task-book with the specific activities of the invention condition to one student, and then a task-book with the specific activities of the fully guided condition to the next student he encountered.

\subsubsection{Phases for the Two Learning Conditions}

All students went through three learning phases of the same duration. However, the first two phases were different depending on the learning condition the students were assigned.

During the first phase, students in the IPL condition attempted to find solutions to the invention problem of Figure 1. Specifically, they had to invent variability indexes to measure economic inequality 
across four imaginary countries. They were given 12 min for this activity. Concurrently, students in the fully guided condition studied the solutions and concepts associated with this problem. That is, the problem was presented in the form of a worked example, where they could study the solutions of the range, the inter-quartile range, and the standard deviation (Figure S2). This worked example also included prompts to guide students to compare all possible case combinations that the problem presented, following recommendations in [7].

During the second phase, students in the IPL condition studied the solutions for the invention problem. That is, they were given the same worked example that students in the fully guided condition had received in the previous phase. They also had 12 min to study it. Concurrently, students in the fully guided condition solved the practice problem in Figure 2. This was an additional problem given only to the students in this condition, to allow them the opportunity to apply the content learned from the worked example to solve a problem.

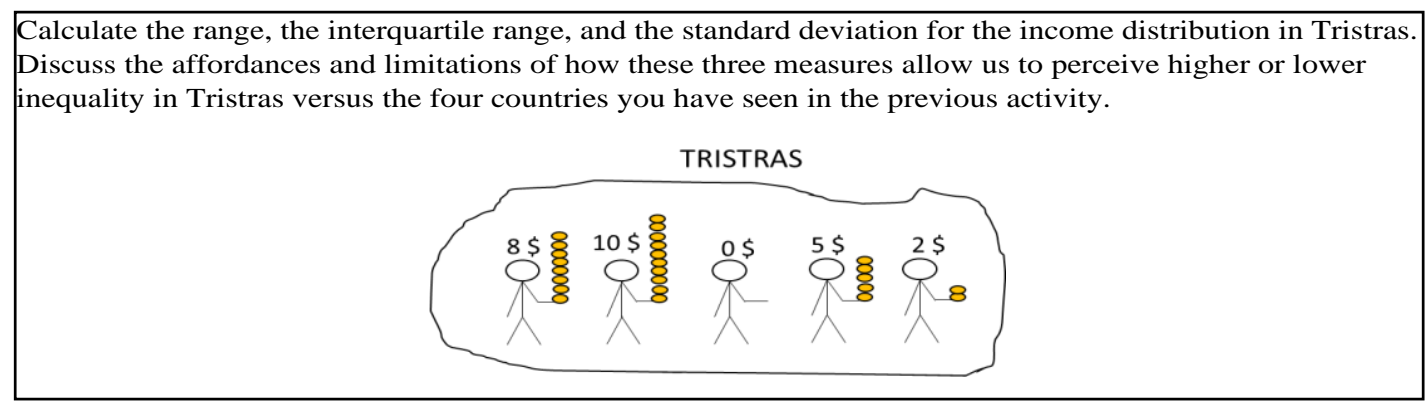

Figure 2. Practice problem used in the fully guided condition.

Finally, during the third phase, students in both conditions received a lecture about statistical variability. The lecture lasted $40 \mathrm{~min}$, with the first $15 \mathrm{~min}$ presented during the first class session, and the remaining $25 \mathrm{~min}$ during the second class session. The lecture included explanations about different variability measures, including partial solutions associated with these measures and problems to apply this content to. A more detailed description of the lecture can be seen in Supplementary Materials (Lecture Description).

\subsubsection{Measurement of Dependent Variables}

Emotions were measured at the end of each of the three learning phases described in the previous section. Students were given 2 min to self-report the emotions they experienced during each phase. Learning was measured in the second session at the end of the learning process, with a post-test that lasted $25 \mathrm{~min}$.

\subsection{Measures and Coding}

\subsubsection{Previous Knowledge Pre-Test}

The pre-test was adapted from a reliable pre-test used in a previous study [28] that covered content relevant to the topic of statistical variability, such as central tendency and graphical representations of distributions. However, items were added to cover other relevant content such as types of variables according to level of measurement, and measures of position. Two versions were created, one in Spanish and a second in English. The Spanish version was used in this study. Detailed information of the items in both languages and about how they were scored can be found in Supplementary Materials (Pre-test). The total possible score ranged from 0 to 8 . The reliability found in this study was low $(\alpha=0.422)$. 


\subsubsection{Emotions}

A Spanish adaptation of the Short Version of the Epistemically-Related Emotions Scale [17] was used. The scale covered seven emotions: surprise, curiosity, enjoyment, confusion, anxiety, frustration and boredom. It consisted of seven items that asked students about the intensity with which they had experienced each emotion during the learning activity that had just ended. Students answered with a 5-point Likert Scale that ranged from 1 (Not at all) to 5 (Very strong). The Spanish adaptation used in the present study is shown in the Supplementary Materials (Emotions Questionnaire).

\subsubsection{Learning Measures}

To measure knowledge acquired by the students, we adapted a reliable post-test that had been used in a previous study to measure their knowledge about standard deviation [28]. In this adaptation, some items were added to cover specific content about other variability measures. The post-test comprised 12 items. Three items measured procedural knowledge (e.g., knowing how to calculate the standard deviation), six items measured conceptual knowledge (e.g., reasoning about components of the standard deviation formula), and three items measured transfer of knowledge (e.g., using the standard deviation formula to infer how to standardize scores). Additionally, a global score of general acquired knowledge was calculated by summing the score of all 12 items. Two language versions were created for this post-test, a Spanish and an English version. The Spanish version was used for this study. Detailed information of the items and scoring regime in both languages can be found in Supplementary Materials (Learning Post-test). The internal reliability of this post-test was low $(\alpha=0.300)$.

\subsection{Data Analysis}

We used non-parametric tests to analyze the outcomes because most of the dependent variables did not fulfill the normality assumption to conduct parametric tests, as indicated by Kolmogorov-Smirnov tests. Indicators for skewness and kurtosis can be seen in Table 1 for each variable.

To evaluate our first question of whether the IPL condition was more effective in promoting learning than the fully guided condition, we used several Mann-Whitney $U$ tests that compared the learning outcomes obtained in the two learning conditions (Table 2). To evaluate our second question about whether students in these two conditions experienced different intensities of emotions, we used Mann-Whitney $U$ tests that compared differences of emotions between the two learning conditions in each learning phase (Table 3). We also explored the means and standard errors for each emotion visually, along with the three learning phases in each condition (Figure 3). To explore the third question of whether the presence and intensity of different emotions was associated with learning, we used Spearman correlations between the intensity of emotions experienced in each learning phase and general acquired knowledge, segregating the results by the two learning conditions (Table 4). Finally, to explore our fourth question of whether previous knowledge was associated with different emotions and with learning, we conducted Spearman correlations between previous knowledge, emotions experienced in each learning phase, and general acquired knowledge, segregating the results by learning conditions (Table 4). A significance level of $p<0.05$ was set for all analyses. 


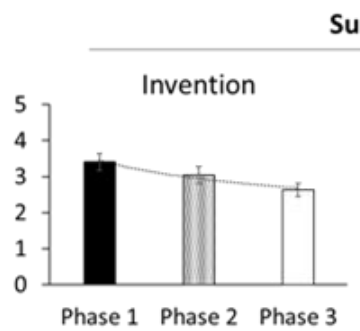

Surprise

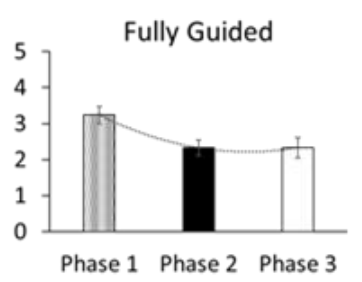

Enjoyment
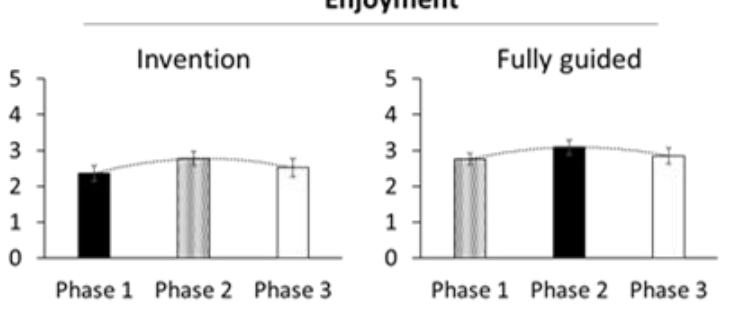

Anxiety
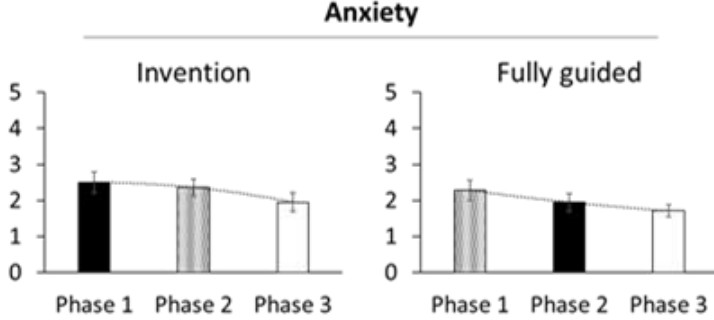

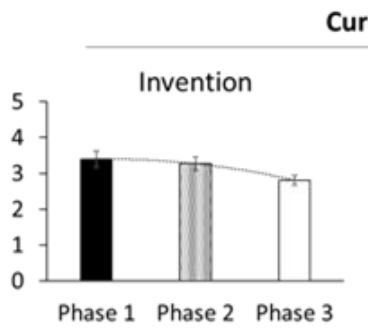

Curiosity
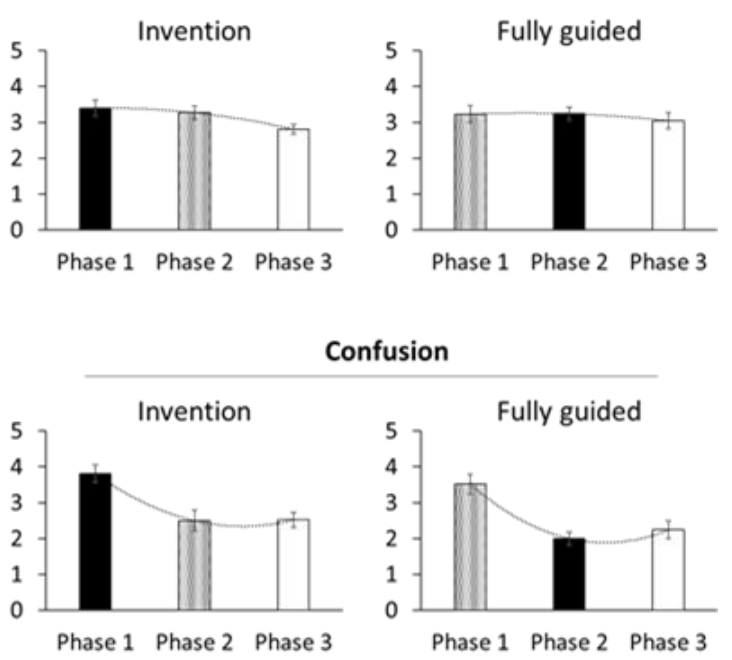

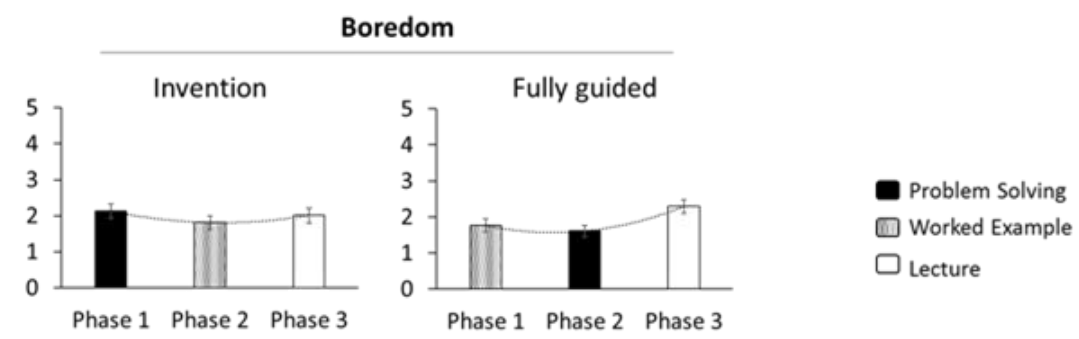

Figure 3. Variation in the intensity with which students experienced each of the seven emotions during the three learning phases of the two learning conditions. The bars represent the means, and the error bars in each bar represent the standard error of the means. Note that for the invention condition, the first phase is problem solving and the second phase is studying the worked example, while for the fully guided condition the order of these two types of activities is inversed.

\section{Results}

\subsection{Description of the Variables}

Table 1 shows means, standard deviations, skewness and kurtosis values for the studied variables, that is, the learning and emotional variables, with the latter presented in the three different learning phases of the experiment. As can be observed, participants experienced the different emotions with different intensities across the different phases. Higher intensities were observed in the initial phase of learning (means $>3$ for surprise, curiosity, confusion and frustration) than in the following phases (means $<3$ for all emotions, except for curiosity in the second phase). This decrease was more accentuated for negative emotions, to the point where the emotions of anxiety and frustration were the least frequently reported emotions occurring during the lecture in phase 3. 
Table 1. Descriptive statistics for the total sample: learning and emotional variables $(n=43)$.

\begin{tabular}{|c|c|c|c|c|}
\hline Variable & Mean & SD & Skewness & Kurtosis \\
\hline Previous knowledge & 3.91 & 1.36 & -0.063 & -1.102 \\
\hline Procedural knowledge & 2.61 & 0.50 & -0.444 & -1.893 \\
\hline Conceptual knowledge & 4.07 & 1.11 & -0.143 & -0.063 \\
\hline Transfer of knowledge & 1.09 & 0.95 & 0.161 & -1.242 \\
\hline General acquired knowledge & 7.77 & 1.68 & -0.090 & -0.750 \\
\hline Surprise $^{1}$ & 3.51 & 1.06 & -0.204 & -0.425 \\
\hline Curiosity $^{1}$ & 3.51 & 1.03 & -0.101 & -0.520 \\
\hline Enjoyment ${ }^{1}$ & 2.56 & 0.93 & 0.099 & 0.035 \\
\hline Confusion ${ }^{1}$ & 3.67 & 1.19 & -0.570 & -0.709 \\
\hline Anxiety ${ }^{1}$ & 2.40 & 1.31 & 0.604 & -0.706 \\
\hline Frustration ${ }^{1}$ & 3.21 & 1.30 & -0.477 & -0.875 \\
\hline Boredom ${ }^{1}$ & 1.95 & 0.90 & 0.714 & -0.133 \\
\hline Surprise $^{2}$ & 2.70 & 1.10 & 0.419 & -0.443 \\
\hline Curiosity $^{2}$ & 3.26 & 0.85 & -0.282 & 0.177 \\
\hline Enjoyment ${ }^{2}$ & 2.93 & 0.95 & 0.144 & -0.175 \\
\hline Confusion $^{2}$ & 2.256 & 1.17 & 0.760 & -0.319 \\
\hline Anxiety $^{2}$ & 2.163 & 1.15 & 0.839 & -0.020 \\
\hline Frustration ${ }^{2}$ & 2.186 & 1.13 & 0.326 & -1.364 \\
\hline Boredom $^{2}$ & 1.721 & 0.82 & 0.839 & -0.189 \\
\hline Surprise $^{3}$ & 2.488 & 1.10 & 0.144 & -0.837 \\
\hline Curiosity $^{3}$ & 2.928 & 0.87 & 0.378 & 0.213 \\
\hline Enjoyment ${ }^{3}$ & 2.690 & 1.09 & 0.426 & -0.317 \\
\hline Confusion ${ }^{3}$ & 2.381 & 1.06 & 0.718 & 0.203 \\
\hline Anxiety $^{3}$ & 1.833 & 1.01 & 0.947 & -0.265 \\
\hline Frustration ${ }^{3}$ & 1.952 & 1.15 & 1.014 & -0.021 \\
\hline Boredom $^{3}$ & 2.190 & 0.92 & 0.399 & -0.546 \\
\hline
\end{tabular}

${ }^{1}$ Emotional variables phase $1 ;{ }^{2}$ Emotional variables phase $2 ;{ }^{3}$ Emotional variables phase 3.

\subsection{Effects of IPL on Learning}

Table 2 shows the means and standard deviations of the previous knowledge and learning variables for both groups (invention and fully guided). As can be observed, in comparison to the fully guided group, the means of the invention group were generally higher, with the exception of procedural knowledge.

Table 2. Between-group differences in previous knowledge and learning outcomes $(n=43)$.

\begin{tabular}{ccccc}
\hline Outcome & $\begin{array}{c}\text { Invention Group } \\
\boldsymbol{M}(\boldsymbol{S D})\end{array}$ & $\begin{array}{c}\text { Fully Guided Group } \\
\boldsymbol{M}(\boldsymbol{S D})\end{array}$ & $\boldsymbol{p}$ & $\boldsymbol{d}$ \\
\hline Previous knowledge & $4.05(1.33)$ & $3.76(1.41)$ & 0.557 & 0.20 \\
Procedural knowledge & $2.59(0.50)$ & $2.61(0.50)$ & 0.852 & -0.03 \\
Conceptual knowledge & $4.52(1.03)$ & $3.60(1.00)$ & 0.007 & 0.89 \\
Transfer of knowledge & $1.27(0.98)$ & $0.90(0.89)$ & 0.228 & 0.39 \\
General acquired knowledge & $8.39(1.71)$ & $7.12(1.39)$ & 0.016 & 0.91 \\
\hline
\end{tabular}

Concretely, the Mann-Whitney U tests indicated that statistically significant differences between groups were found in conceptual knowledge and general acquired knowledge, with large effect sizes (Table 2). Further, importantly, the groups did not significantly differ in previous knowledge ( $p=0.557)$.

\subsection{Effects of IPL on Emotional Reactions}

When comparing the differences in emotions experienced by students in the IPL condition (invention group) and those who were introduced to the concepts with a worked example (fully guided group), the means indicated that both groups showed similar tendencies (Table 3). Mann-Whitney 
$\mathrm{U}$ tests only identified a statistically significant difference for the surprise emotion during phase 2 $(p=0.032)$ with a medium effect size $(d=0.675)$. The invention group showed higher scores in this variable than the fully guided group. However, it was not felt that this result was particularly relevant because it could easily be explained by the fact that, in this phase, the invention group started receiving explanations with the worked example, while the fully guided group practiced with the concepts they had just covered in the previous phase, which, in terms of content, would be expected to be less surprising.

Table 3. Between-group differences in emotional reactions: Moments 1 to $3(n=43)$.

\begin{tabular}{ccccc}
\hline & \multicolumn{2}{c}{ Invention Group $(\boldsymbol{n}=\mathbf{2 2})$} & Fully Guided Group $(\boldsymbol{n}=\mathbf{2 1})$ \\
\hline Variable & Mean & SD & Mean & SD \\
\hline Surprise $^{1}$ & 3.41 & 1.05 & 3.24 & 1.09 \\
Curiosity $^{1}$ & 3.41 & 1.18 & 3.62 & 0.86 \\
Enjoyment $^{1}$ & 2.36 & 1.05 & 2.76 & 0.76 \\
Confusion $^{1}$ & 3.82 & 1.14 & 3.52 & 1.24 \\
Anxiety $^{1}$ & 2.50 & 1.37 & 2.29 & 1.27 \\
Frustration $^{1}$ & 3.46 & 1.34 & 2.95 & 1.24 \\
Boredom $^{1}$ & 2.14 & 0.94 & 1.76 & 0.83 \\
Surprise $^{2}$ & 3.05 & 1.09 & 2.33 & 1.02 \\
Curiosity $^{2}$ & 3.27 & 0.88 & 3.23 & 0.83 \\
Enjoyment $^{2}$ & 2.77 & 0.92 & 3.10 & 0.94 \\
Confusion $^{2}$ & 2.50 & 1.40 & 2.00 & 0.84 \\
Anxiety $^{2}$ & 2.36 & 1.13 & 1.95 & 1.16 \\
Frustration $^{2}$ & 2.14 & 1.13 & 2.24 & 1.18 \\
Boredom $^{2}$ & 1.82 & 0.91 & 1.62 & 0.74 \\
Surprise $^{3}$ & 2.64 & 0.85 & 2.33 & 1.32 \\
Curiosity $^{3}$ & 2.81 & 0.68 & 3.05 & 1.02 \\
Enjoyment $^{3}$ & 2.52 & 1.17 & 2.86 & 1.01 \\
Confusion $^{3}$ & 2.52 & 0.98 & 2.24 & 1.14 \\
Anxiety $^{3}$ & 1.95 & 1.20 & 1.71 & 0.78 \\
Frustration $^{3}$ & 2.05 & 1.16 & 1.86 & 1.15 \\
Boredom $^{3}$ & 2.10 & 0.94 & 2.29 & 0.90 \\
\hline (1) & & &
\end{tabular}

${ }^{1}$ Emotional variables phase $1 ;{ }^{2}$ Emotional variables phase $2 ;{ }^{3}$ Emotional variables phase 3.

As for the variations in the students' emotional reactions across the different phases of the experiment, Figure 3 and Table 3 show that both groups followed similar patterns, characterized by slight reductions in the emotions over time, except for enjoyment and boredom. Larger reductions were observable in the case of confusion and frustration, with these emotions being more intense in phase 1 than in the subsequent phases of the experiment. It is also interesting to note that boredom decreased during phase 2 and increased again in phase 3, especially in the fully guided group, with the increase coinciding in both cases with the lecture. As for enjoyment, there is a slight increase in phase 2 , matching the studying of the worked example in the invention group and problem solving in the fully guided group.

\subsection{Association between Previous Knowledge, Acquired Knowledge and Emotions}

General acquired knowledge was not significantly associated with previous knowledge in either the invention group (rho $=0.375, p=0.086$ ) or the fully guided group (rho $=0.099, p=0.670$ ), although the intensity of this association was stronger for the invention group.

The associations between the emotions experienced across the different learning phases with previous knowledge and with general acquired knowledge are shown in Table 4. As can be observed, in phase 1 the only statistically significant associations found in the invention group were for enjoyment, which was associated with both previous knowledge and general acquired knowledge. 
These associations were positive, thus those students who experienced higher enjoyment during the invention activity were also the ones who had more previous knowledge before the lesson, and who had acquired higher knowledge by the end of the lesson. In the case of the fully guided group, only one statistically significant association was found, specifically between boredom and previous knowledge. This relationship was negative, indicating that those students with less previous knowledge were the ones who experienced more boredom while studying the worked example during the first phase.

Table 4. Spearman correlations of previous knowledge and general acquired knowledge with the emotions experienced during the three learning phases across the two learning conditions.

\begin{tabular}{|c|c|c|c|c|c|}
\hline \multirow[b]{2}{*}{ Phase } & \multirow[b]{2}{*}{ Emotions } & \multicolumn{2}{|c|}{$\begin{array}{c}\text { Invention Group } \\
(n=22)\end{array}$} & \multicolumn{2}{|c|}{$\begin{array}{l}\text { Fully Guided Group } \\
\qquad(n=21)\end{array}$} \\
\hline & & $\begin{array}{c}\text { Previous } \\
\text { Knowledge } \\
\text { Rho }(p)\end{array}$ & $\begin{array}{c}\text { General } \\
\text { Acquired } \\
\text { Knowledge } \\
\text { Rho }(p)\end{array}$ & $\begin{array}{c}\text { Previous } \\
\text { Knowledge } \\
\text { Rho }(p)\end{array}$ & $\begin{array}{c}\text { General } \\
\text { Acquired } \\
\text { Knowledge } \\
\text { Rho }(p)\end{array}$ \\
\hline \multirow[t]{7}{*}{ Phase 1} & Surprise & $0.122(0.588)$ & $0.053(0.814)$ & $-0.091(0.694)$ & $0.128(0.580)$ \\
\hline & Curiosity & $0.291(0.188)$ & $0.153(0.497)$ & $-0.201(0.382)$ & $0.019(0.936)$ \\
\hline & Enjoyment & $0.433(0.044)$ * & $0.447(0.037)^{*}$ & $0.037(0.872)$ & $0.121(0.601)$ \\
\hline & Confusion & $-0.246(0.269)$ & $-0.218(0.330)$ & $-0.181(0.432)$ & $0.063(0.787)$ \\
\hline & Anxiety & $-0.118(0.602)$ & $-0.005(0.982)$ & $-0.128(0.582)$ & $0.375(0.094)$ \\
\hline & Frustration & $-0.200(.371)$ & $-0.246(0.269)$ & $-0.235(0.306)$ & $0.277(0.224)$ \\
\hline & Boredom & $-0.349(0.112)$ & $-0.181(0.419)$ & $-0.563(0.008)$ * & $-0.082(0.723)$ \\
\hline \multirow[t]{7}{*}{ Phase 2} & Surprise & $-0.001(0.995)$ & $-0.493(0.020) *$ & $-0.186(0.420)$ & $0.094(0.685)$ \\
\hline & Curiosity & $0.152(0.501)$ & $-0.274(0.339)$ & $-0.418(0.059)$ & $0.039(0.867)$ \\
\hline & Enjoyment & $0.165(0.464)$ & $0.058(0.797)$ & $-0.020(0.933)$ & $0.295(0.195)$ \\
\hline & Confusion & $-0.038(0.866)$ & $-0.173(0.443)$ & $-0.085(0.715)$ & $-0.128(0.579)$ \\
\hline & Anxiety & $-0.075(0.741)$ & $-0.210(0.349)$ & $-0.099(0.670)$ & $0.328(0.147)$ \\
\hline & Frustration & $0.091(0.686)$ & $-0.102(0.650)$ & $0.006(0.980)$ & $-0.003(0.990)$ \\
\hline & Boredom & $0.047(0.836)$ & $0.170(0.451)$ & $-0.235(0.305)$ & $-0.341(0.130)$ \\
\hline \multirow[t]{7}{*}{ Phase 3} & Surprise & $-0.027(0.905)$ & $-0.062(0.783)$ & $-0.144(0.535)$ & $0.127(0.583)$ \\
\hline & Curiosity & $0.439(0.047) *$ & $0.028(0.904)$ & $-0.511(0.018)$ * & $0.048(0.835)$ \\
\hline & Enjoyment & $0.032(0.891)$ & $0.060(0.797)$ & $-0.305(0.180)$ & $-0.093(0.687)$ \\
\hline & Confusion & $-0.418(0.059)$ & $-0.004(0.985)$ & $0.037(0.873)$ & $0.170(0.460)$ \\
\hline & Anxiety & $-0.186(0.420)$ & $-0.128(0.580)$ & $-0.065(0.781)$ & $0.101(0.662)$ \\
\hline & Frustration & $-0.321(0.156)$ & $-0.224(0.330)$ & $-0.145(0.531)$ & $-0.067(0.774)$ \\
\hline & Boredom & $0.039(0.865)$ & $0.331(0.170)$ & $0.095(0.681)$ & $-0.028(0.903)$ \\
\hline
\end{tabular}

For phase 2, a statistically significant association was only found between surprise and general acquired knowledge in the invention group. This association was negative, indicating that the students who experienced higher levels of surprise at this point showed lower levels of achievement at the end of the experiment. This relationship was not statistically significant in the fully guided group.

Finally, the only statistically significant association during phase 3 was between curiosity and previous knowledge. In the case of the invention group, this association was positive, while in the case of the fully guided group, it was negative.

\section{Discussion}

This study evaluated whether the introduction of invention activities into a university statistics class was an effective method for enhancing learning, and explored how this might be influenced by the emotional reactions of students.

The results supported the suggestion that IPL was an effective technique for promoting deep learning. Students who began the learning process with invention before instruction acquired more conceptual knowledge than students who began with a worked example. This difference was large; 
the two groups differed by 0.92 standard deviations. This result is consistent with the previous literature $[15,16]$, and our study contributes as it shows that these previous studies can be generalized to university students, a population scarcely studied in the context of IPL [16,25]. Yet, it is important to note that the advantage in conceptual knowledge was not accompanied with a significant advantage in transfer, as is generally found in the literature [16]. Although this advantage could be observed at the descriptive level, it did not reach statistical significance.

When the results were evaluated in terms of procedural knowledge, that is, in the ability to reproduce learned procedures, no differences were found between IPL and introducing the concepts with a worked example. This result is also consistent with the previous literature [16], and might be explained by the fact that procedural knowledge can be supported just by memorization of content. The cognitive processes supported by IPL refer to critical reflection about conceptual structures [5], or to awareness of knowledge gaps [11], but memorization can occur regardless of these processes. Indeed, performance in procedural knowledge was remarkably high in the whole sample. Almost $60 \%$ of the students were able to correctly answer all procedural knowledge items, which included questions about calculation and the interpretation of variability measures.

Regarding emotions, we had hypothesized that students doing the invention activity would experience a higher emotional response than students being initially prepared with the worked example, both in negative emotions and positive emotions. However, students in both conditions reported similar emotional responses across all learning phases. In both conditions, emotions of confusion, frustration, surprise and anxiety tended to decrease as students went through the different learning phases. In both learning conditions we attributed this to the novelty of the first activity. In the invention condition, students might have also felt negative emotions because of the cognitive load or the over-challenge they experienced while working on the invention problem; however, these emotions might have been abated, due to the reduced challenge, once they started receiving feedback and instruction in the next phase. For students in the fully guided condition, the initial levels of frustration and anxiety might have been due to them being unfamiliar with starting a lesson with a worked example.

Despite the similar pattern of emotions seen across both learning conditions, the associations found between emotions and learning were interesting. Enjoyment during the invention activity was strongly associated with learning. This association was much stronger than associations between enjoyment and learning found in other learning contexts [22]. Indeed, in the present study this association was very weak and not statistically significant for the fully guided condition. A potential explanation is that the motivational effects of enjoyment might be more pronounced during invention tasks than in other traditional tasks. Enjoyment during invention activities could be crucial to fostering a relaxed disposition that allows the exploration of personal ideas, while in other learning contexts the ideas to explore are explicitly told to students. With regard to this, the previous literature has found that enjoyment during problem solving is a predictor of deep learning processes [20,21].

In contrast, the relations between negative emotions experienced during the invention activity and knowledge acquired were not significant. This can be explained by the fact that negative emotions can have both negative and positive effects on learning. On the one hand, these emotions can contribute to the experience of cognitive overload and reduce intrinsic motivation [22]. However, on the other hand, they might also have activating effects if experienced transitionally [20,24]. As discussed before, in IPL the potential for students to feel over-challenged is only expected during the invention activity.

Finally, of great interest is exploring the students' predispositions that might explain these emotional and learning patterns. In this study, we observed that previous knowledge can help explain the association between learning and enjoyment during invention. In the invention condition, enjoyment during the invention phase was associated with both previous knowledge and acquired knowledge, while these associations were not significant in the fully guided approach. A potential explanation is that students with higher previous knowledge have more resources for facing the challenge of invention tasks than their peers with lower previous knowledge, which would potentially 
lead them to approach the task with more confidence, therefore increasing the likelihood that they would enjoy the learning experience. Yet, it is important to note that the association between previous knowledge and acquired knowledge did not reach significant levels. Future studies can continue exploring these questions with larger samples. Especially interesting is the question of whether those students who have lower previous knowledge would benefit more from alternative approaches, that provide a higher level of guidance, than from IPL. It is also of interest to consider a greater variety of students' predispositions, such as metacognitive abilities, divergent thinking abilities and previous motivation. A more specific discussion about all associations found between previous knowledge, emotions and acquired knowledge can be found in Appendix A.

\subsection{New Technologies and Educational Applications}

This study supports the application of IPL in general educational practice as a strategy to promote conceptual knowledge. Promoting understanding of the concepts learned and their capacity to transfer this knowledge to new contexts is of great relevance to preparing students for the important challenges and decisions that we face as individuals and societies [1,2].

IPL also offers new opportunities within the contexts of new technologies and distance education. No extra support is required to perform invention activities, such that students can either perform them during class or as virtual homework assignments. For example, a recent study suggested that IPL could be applied to the paradigm of flipped classroom, using invention activities as a home assignment that would later be complemented in class [29].

Finally, based on the important role that emotions appear to play in the learning acquired through invention, the application of this approach in combination with interventions that foster emotional awareness or emotional self-regulation is of interest. For example, within the context of new technologies, there are new applications such as Triple Task [30], in which students report the cognitive processes they experience at each stage while completing a learning activity. Once the task is finished, the application automatically draws a graph of the learning process reported during the activity.

\subsection{Limitations and Future Studies}

This study contributed to supporting the efficacy of IPL in a university setting, and it has been the first we know of to explore emotional reactions while using the method. However, it has some limitations. Firstly, due to the specificity of the content covered, the pre-test and post-test are not previously validated instruments. Although they were constructed based on reliable instruments, the internal reliability observed in this study was small. Secondly, the sample was small, and so we likely failed to identify some important effects related to emotions and learning. Thirdly, it is important to note that the invention phase in this study was very short. The two learning conditions differed only in $24 \mathrm{~min}$ of learning activities. It is of great importance to gather future evidence that confirms the efficacy of IPL with such short implementation times. Last, cognitive and motivational predispositions were not assessed in this study. These components could help to increase the external and internal validity of the results, and to identify differing profiles of students with regard to the emotions experienced during invention activities.

Future studies should explore these predispositions with larger samples, including the evaluation of predispositions such as divergent thinking skills, critical thinking skills, intelligence, metacognition, previous knowledge and previous motivation [6,9]. Future studies can also study the dynamics of emotions more thoroughly. Previous studies have explored how the experiencing of one emotion leads to the experiencing of other emotions and different learning processes [20,21]. Such a paradigm could be applied to IPL, especially with the help of applications that facilitate the registering of the emotions and mental processes that students experience during learning activities, such as the Triple Task [30]. Of great interest as well is how these applications can be used to foster awareness and the self-regulation of emotions during invention activities. Finally, it is important to study the long-term 
effects of implementing IPL regularly as an intervention that can help promote the development of general skills, such as critical thinking.

Supplementary Materials: The following are available online at http://www.mdpi.com/2071-1050/12/18/7306/s1, Pre-test, Figure S1: Study Design, Figure S2: Worked Example, Lecture Description, Emotions Questionnaire, Learning Post-test.

Author Contributions: Conceptualization, all authors; methodology, E.G.-C., T.G., and M.C..; formal analysis, E.G.-C. and T.G.; resources, J.C.N. and M.C.; data curation, E.G.-C.; original draft preparation, E.G.-C. and T.G.; review and editing, T.G. and C.R.; supervision, T.G. and J.C.N.; funding acquisition, J.C.N. and C.R. All authors have read and agreed to the published version of the manuscript.

Funding: This research was funded by the Principality of Asturias, Spain, grant number FC-GRUPIN-IDI/ 2018/000199, and by a predoctoral grant from the Ministry of Education, Culture and Sports of Spain, grant number FPU16/05802.

Conflicts of Interest: The authors declare no conflict of interest. The funders had no role in the design of the study; in the collection, analyses, or interpretation of data; in the writing of the manuscript, or in the decision to publish the results.

\section{Appendix A. Further Discussion about Correlations between Previous Knowledge, Emotions and General Acquired Knowledge}

In the Discussion section we examined the significant correlation found between previous knowledge and enjoyment during the invention activity of the IPL condition. We also discussed the association found between enjoyment and higher learning. Finally, we have discussed the lack of significant associations found between negative emotions in the invention phase of IPL and general acquired knowledge. However, there are other results that, although not hypothesized, are also interesting to comment on.

Firstly, during the initial phase of the fully guided condition, in which students studied the procedures of several variability measures in a worked example, boredom was significantly and negatively associated with previous knowledge. Students with lower previous knowledge felt more bored. This effect might be explained by the fact that students with lower previous knowledge found the content difficult and therefore did not apply themselves fully to the activity. However, it is important to note that previous knowledge was not associated with boredom in later phases of learning, where the students had to apply the concepts just learned to a problem-solving activity. This was an activity wherein students adopted an active role, so it was possibly motivating to students with both high and low levels of previous knowledge. This result is consistent with authors who emphasize the importance of including problem-solving activities, either in the context of IPL or in more guided approaches [31]. Further, in accordance with this argument, it is important to note that, although boredom in the first phase was associated with lower previous knowledge, it was not associated with general acquired knowledge at the end of the lesson.

Another significant finding was the negative association between surprise in the second phase of IPL and acquired knowledge, rho $=-0.493, p=0.020$. The more surprised students felt, the less knowledge they had acquired at the end. We did not expect this result. Surprise is an activating emotion that can motivate learning [17]. Yet, it is possible that the students who felt more surprise had more erroneous preconceptions about statistical variability, and in turn, these students with more erroneous preconceptions experienced more problems learning the content. It is important to note that this was the phase in which these students started to receive explanations.

Finally, and more surprisingly, the association between previous knowledge and curiosity in the third phase of learning was significantly positive in the IPL group, but significantly negative in the fully guided group. A possible explanation is that previous knowledge, when combined with the opportunity to invent, could drive higher curiosity in the later learning phases. Students with more previous knowledge might find more opportunities to develop their ideas during invention, and then feel more curious about connecting these developed ideas with the content covered in the lecture. However, when there is not an invention phase, those students with higher previous knowledge might 
find the lecture less interesting and more repetitive. Without the opportunity to personally develop their ideas during the invention phase, they could miss connections between the new knowledge and their previous knowledge.

It is important to consider, nevertheless, that many associations were tested in this study, and some associations might be significant just because of chance. It would be interesting to see if the different effects found here are replicated in larger samples.

\section{References}

1. Napal, M.; Mendióroz-Lacambra, A.M.; Peñalva, A. Sustainability teaching tools in the digital age. Sustainability 2020, 12, 3366. [CrossRef]

2. United Nations. Transforming Our World: The 2030 Agenda for Sustainable Development. Available online: https://sustainabledevelopment.un.org/post2015/transformingourworld/publicationNations (accessed on 31 May 2020).

3. Schwartz, D.L.; Martin, T. Inventing to prepare for future learning: The hidden efficiency of encouraging original student production in statistics instruction. Cogn. Instr. 2004, 22, 129-184. [CrossRef]

4. Schwartz, D.L.; Bransford, J.D. A time for telling. Cogn. Instr. 1998, 16, 475-5223. [CrossRef]

5. Schwartz, D.L.; Chase, C.C.; Oppezzo, M.A.; Chin, D.B. Practicing versus inventing with contrasting cases: The effects of telling first on learning and transfer. J. Educ. Psychol. 2011, 103, 759-775. [CrossRef]

6. Glogger-Frey, I.; Gaus, K.; Renkl, A. Learning from direct instruction: Best prepared by several self-regulated or guided invention activities? Learn. Instr. 2017, 51, 26-35. [CrossRef]

7. Glogger-Frey, I.; Fleischer, C.; Grueny, L.; Kappich, J.; Renkl, A. Inventing a solution and studying a worked solution prepare differently for learning from direct instruction. Learn. Instr. 2015, 39, 72-87. [CrossRef]

8. Kapur, M.; Bielaczyc, K. Designing for productive failure. J. Learn. Sci. 2012, 21, 45-83. [CrossRef]

9. Belenky, D.M.; Nokes-Malach, T.J. Motivation and transfer: The role of mastery-approach goals in preparation for future learning. J. Learn. Sci. 2012, 21, 399-432. [CrossRef]

10. Kapur, M. Productive failure in learning the concept of variance. Instr. Sci. 2012, 40, 651-672. [CrossRef]

11. Loibl, K.; Rummel, N. Knowing what you don't know makes failure productive. Learn. Instr. 2014, 34, 74-85. [CrossRef]

12. Clark, R.; Kirschner, P.A.; Sweller, J. Putting students on the path to learning: The case for fully guided instruction. Am. Educ. 2012, 36, 6-11.

13. Sweller, J.; van Merrienboer, J.J.G.; Paas, F. Cognitive architecture and instructional design: 20 years later. Educ. Psychol. Rev. 2019, 31, 261-292. [CrossRef]

14. Likourezos, V.; Kalyuga, S. Instruction-first and problem-solving-first approaches: Alternative pathways to learning complex tasks. Instr. Sci. 2017, 45, 195-219. [CrossRef]

15. Darabi, A.; Arrington, T.L.; Sayilir, E. Learning from failure: A meta-analysis of the empirical studies. Educ. Technol. Res. Dev. 2018, 66, 1101-1118. [CrossRef]

16. Loibl, K.; Roll, I.; Rummel, N. Towards a theory of when and how problem solving followed by instruction supports learning. Educ. Psychol. Rev. 2017, 29, 693-715. [CrossRef]

17. Pekrun, R.; Vogl, E.; Muis, K.R.; Sinatra, G.M. Measuring emotions during epistemic activities: The epistemically-related emotion scales. Cogn. Emot. 2017, 31, 1268-1276. [CrossRef]

18. Muis, K.R. The role of epistemic beliefs in self-regulated learning. Educ. Psychol. 2007, 42, 173-190. [CrossRef]

19. Boekaerts, M. Emotions, Emotion Regulation, and Self-Regulation of Learning. In Handbook of Self-Regulation of Learning and Performance; Routledge: New York, NY, USA, 2011; pp. 408-425.

20. Di Leo, I.; Muis, K.R.; Singh, C.A.; Psaradellis, C. Curiosity. Confusion? Frustration! The role and sequencing of emotions during mathematics problem solving. Contemp. Educ. Psychol. 2019, 58, 121-137. [CrossRef]

21. Muis, K.R.; Psaradellis, C.; Lajoie, S.P.; Di Leo, I.; Chevrier, M. The role of epistemic emotions in mathematics problem solving. Contemp. Educ. Psychol. 2015, 42, 172-185. [CrossRef]

22. Loderer, K.; Pekrun, R.; Lester, J.C. Beyond cold technology: A systematic review and meta-analysis on emotions in technology-based learning environments. Learn. Instr. 2018, 101162. [CrossRef]

23. Pekrun, R.; Goetz, T.; Frenzel, A.C.; Barchfeld, P.; Perry, R.P. Measuring emotions in students' learning and performance: The achievement emotions questionnaire (AEQ). Contemp. Educ. Psychol. 2011, 36, 36-48. [CrossRef] 
24. D'Mello, S.; Graesser, A. Confusion. In International Handbook of Emotions in Education; Alexander, P.A., Pekrun, R., Linnenbrink-Garcia, L., Eds.; Taylor and Francis: New York, NY, USA, 2014; pp. 289-310.

25. Weaver, J.P.; Chastain, R.J.; DeCaro, D.A.; DeCaro, M.S. Reverse the routine: Problem solving before instruction improves conceptual knowledge in undergraduate physics. Contemp. Educ. Psychol. 2018, 52, 36-47. [CrossRef]

26. González-Cabañes, E.; García, T.; Núñez, C.; Rodríguez, C. Problem-Solving before instruction (PS-I): A protocol for assessment and intervention in students with different abilities. J. Vis. Exp.. under review.

27. Newman, P.M.; DeCaro, M.S. Learning by exploring: How much guidance is optimal? Learn. Instr. 2019, 62, 49-63. [CrossRef]

28. Kapur, M. Productive failure in learning math. Cogn. Sci. 2014, 38, 1008-1022. [CrossRef]

29. Song, Y.; Kapur, M. How to flip the classroom-"Productive Failure or Traditional Flipped Classroom" pedagogical design? J. Educ. Technol. Soc. 2017, 20, 292.

30. García, T.; Betts, L.; González-Castro, P.; González-Pienda, J.A.; Rodriguez, C. On-Line assessment of the process involved in Maths problem-solving in fifth and sixth grade students: Self-Regulation and achievement. RELIME. Rev. Latinoam. Investig. Matemática Educ. 2016, 19, 165-186. [CrossRef]

31. Trninic, D. Instruction, repetition, discovery: Restoring the historical educational role of practice. Instr. Sci. 2018, 46, 133-153. [CrossRef]

(C) 2020 by the authors. Licensee MDPI, Basel, Switzerland. This article is an open access article distributed under the terms and conditions of the Creative Commons Attribution (CC BY) license (http://creativecommons.org/licenses/by/4.0/). 